Vol. 5, No. 1, 2018

UDC 658.589

A. Boychuk

PhD Student, Assistant

Lviv Polytechnic National University

\title{
CONTROL OVER THE IMPLEMENTATION OF THE INNOVATIVE DEVELOPMENT PROGRAM AND EVALUATION OF ITS EFFICIENCY
}

\begin{abstract}
The peculiarities of control over the implementation of the innovative development program are analyzed. The use of means of indicative control based on the evaluation of the analysis results of both individual indicators and their groups (time, resource and result) in the process of current control over the emergence of deviations and their prompt correction during the implementation of the innovative development program is scientifically substantiated. General principles of the financial efficiency evaluation of the implemented innovative programs are researched. The analysis procedure of financial efficiency of the innovative development program of the enterprise is suggested, which is based on the assumption that a highly effective innovative program should provide improvement of the financial condition of the enterprise and is carried out in several successive steps: the choice of nomenclature of indicators used for the analysis of the financial condition; formation of the reported data on the results of the implementation of the innovative program; direct carrying out of analytical works; generalization of the results of the analysis. The development method of adjusted forms of financial reporting, based on the business operations of the enterprise and connected with an exclusively innovative activity, is suggested. The problem analysis enables to determine the impact of the implementation results of the innovative development program of the enterprise on the indicators of the financial condition, in contrast to the impact of factors associated with a non-innovative activity, in particular, operating or financial.
\end{abstract}

Keywords: innovative program, control, indicator, financial efficiency, evaluation, reporting, financial indicator

\section{Formulation of the problem}

The growth of the role of innovation in the current conditions of entrepreneurship necessitates a complete and objective evaluation of the financial efficiency of the implemented innovative programs, which plays an important role in the process of managing the innovative activity of the enterprise. The methodological tools for evaluating the financial efficiency of innovative development programs developed by Ukrainian and foreign scientists often duplicate methodological approaches for evaluating the investment projects. However, most of them are not suitable for evaluating the financial efficiency since they do not provide tools for analyzing the system of financial and economic indicators of the enterprise. Therefore, there is a need to develop a methodology for analyzing the financial efficiency of the innovative development program of the enterprise, which would fully ensure the objective results of such analysis.

\section{Analysis of recent research and publications}

The issues of the methodology and practice of evaluating the efficiency of the innovative program at the enterprise are examined in the works of many Ukrainian and foreign scientists. A significant contribution to the development of science in this direction is made by O.A. Gavrysh, S. I. Hrytsulenko, O.E. Kuzmin, S.V. Kniaz, E.A. Lyfanova, Yo. M. Petrovych, O.V. Tytova, R. N. Fedosova, A.V. Cherep, N.I. Chukhrai, E.S. Shynkareva, N.V. Shyriayeva and others. Methodological and organizational issues for evaluating the efficiency of the innovative programs are the subject of the thesis research of such Ukrainian scientists as Ye.V. Hnitetsky, K. M. Kashchuk, N.P. Krush, A.E. Nykyforov, K.S. 


\section{A. Boychuk}

Savenko, E.E. Savytsky, D.I. Skvortsov, I. A. Shaiko and others.

Despite the considerable amount of research, the issue of a complete and objective evaluation of the financial efficiency of the implemented innovative program requires further research. The issue of the determination of the financial effect from the implementation of an innovative development program at the enterprise remains unsettled not taking into account the influence of factors related to non-innovative activity, in particular, operational or financial.

The aim of the article is to develop a methodology for analyzing the financial efficiency of the innovative development program of the enterprise, which would fully ensure the objective results of such an analysis.

\section{Presentation of the main material}

Control is an important factor in the efficient management of innovative activities at the enterprise, as well as a means to achieve the established strategic goals of innovative development and related tasks. The implementation of any innovative program without an efficient organization of the control system is foredoomed to failure

In our opinion, one of the efficient methods of current control over the emergence of deviations and their prompt correction during the implementation of the innovative program is the use of the indicative monitoring mechanism.

Recent research demonstrates the efficiency of the use of indicators (as opposed to well- defined, rigid policy indicators) in different areas of management, mainly in macro level planning. M. R. Tymoshchuk [1, p. 304] defines indicative planning as a formation process of a system of indicators that characterize the condition and development of the country's economy and correspond to the state social and economic policy, as well as the development of measures of state influence on social and economic processes in order to achieve the defined indicators. Indicative planning is fundamentally different from policy planning by achieving the goals set in the plan. Its indicators do not have the status of mandatory tasks for certain economic entities, but they are of an advisory and preliminary nature [2, p. 01]. According to M. N. Bidniak [3, p. 31], the control system of indicative management evaluation includes the evaluation of indicative forecast indicators, indicative planning indicators and program indicators.

The method of indicative control consists in the development of a number of indicators of the process under control, i.e. indicative features, the change of which indicates a high possibility of a negative result of the program implementation. The use of indicators enables to evaluate the current condition of the innovative development program implementation of the machine-building enterprise and to identify "bottlenecks" and problem areas of the program's projects. Control involves using the questionnaire as a basic tool in the process of checking the current status of the program to evaluate the admissibility of any violations detected, as well as providing certain recommendations for its results (Fig. 1).

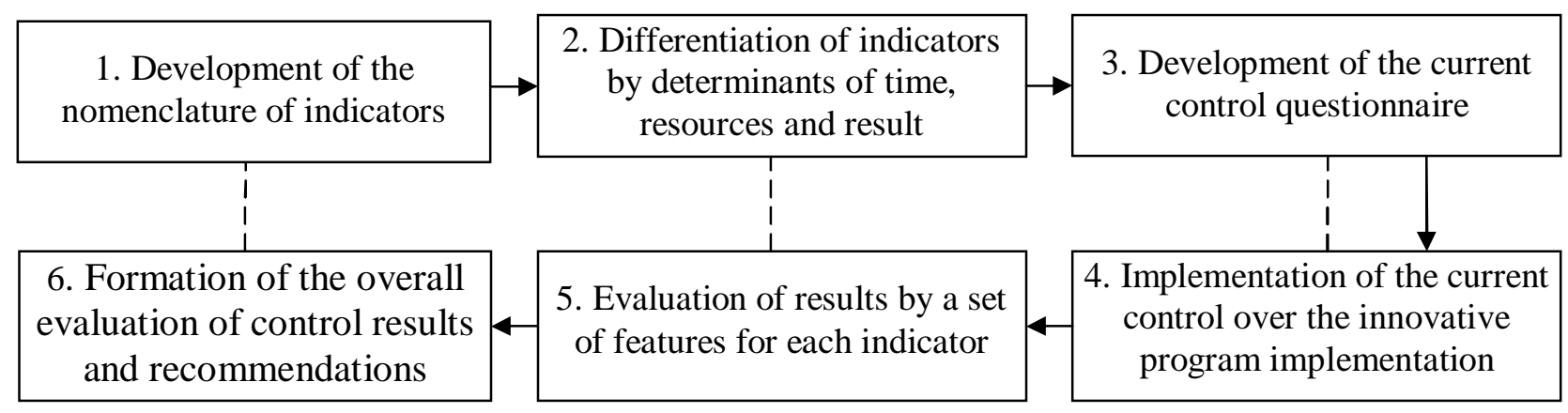

------ - correction

Fig. 1. Mechanism of the current indicative control implementation of the innovative development program of the enterprise

Source: elaborated by the author 
The implementation of the mechanism controlling the innovative development program of the enterprise is to be implemented in six stages: the development of indicators; division of indicators into three groups (time indicators, resource indicators, result indicators); development of the working questionnaire of the controller; direct implementation of control measures and procedures; evaluation of the results of the current control in the context of individual indicators and groups of indicators; preparation of the report and formation of recommendations on the control results.

The control over the implementation of the innovative program takes place according to three main determinants (generalized indicators) of time, resources and result. The division of indicators takes place taking into account the peculiarities of the enterprises of the machine-building industry and critical areas of work on the implementation of the innovative development program.

A generalized indicator of time is a system of features that enables to evaluate the possibility of violating the time of the implementation of the innovative development program. This term is a certain period of time that begins on the next calendar day after the approved date of the project implementation and ends with the scheduled date for its completion.

A generalized indicator of resources is a system of features indicating possible violations of the volumes and quality of the objects of the natural, economic and social environments that are involved in meeting the needs of the enterprise's innovative development. These include financial, material and human resources involved in the implementation of the innovative development program.

A generalized indicator of the result is a system of features that enables to evaluate the possible negative effect of the innovative program implementation. It is closely linked to the abovementioned indicators, but the separation of this category is intended to demonstrate the possibility of obtaining a negative result, even if the rules of time and resources are respected.

The final conclusion in the case of indicative control use over the implementation of the innovative program of the machine-building enterprise can be made only after a detailed analysis of the characteristics (properties) of the detected indicators. The most important properties are the following: systematicity, duration and redundancy.

Systematicity involves repeated and repetitive violations, which results in an increase in the timing of project implementation, in excess of the volume of resources used and/or in the formation of a negative result at individual stages of the project implementation or on the program as a whole. Systematicity may indicate the inactivity of management in addressing the pressing problems of innovation development of the enterprise.

Duration is the time during which there is a violation. We proceed from the assumption that the longer the duration of the negative factors on the resulting feature is, the more harmful the effects of the impact and, consequently, more labourintensive and costly work to correct such influence is. Duration can indicate a lack of proper tools for identifying and correcting problems in the innovative program implementation.

Redundancy is the amount of extra (excess) spent resources and time per unit of performed work, which ultimately affects the efforts to be made to correct existing problems. Capacity indicates the inefficiency of using the risk diversification mechanism in relation to certain aspects of an enterprise's innovative development program: dependence on one source of financing, supplier, contractor, employee-innovator, etc.

Each of the available time, resource and result indicators to evaluate the possibility of achieving a positive final result of the innovative development program implementation should be checked for the presence of deviations according to the criteria of systematicity, duration and redundancy.

The solution of the problem is based on the use of qualitative criteria and methods for their processing (for example, using fuzzy logic methods).

The efficiency of the innovative development program is testified by an excess of the effect of spent resources obtained from its implementation. For innovative projects, the effect can be economic, social, environmental, etc. 


\section{A. Boychuk}

The economic effect obtained in the use of scientific and technical products can be manifested in the growth of labour productivity, increase in the operating time of equipment, reduction of operating costs, cost of production, the capital cost per unit of output of products, increase of its quality, enlargement in the share and profit margins, as well as the improvement of social indicators compared to the available option. The economic effect from the introduction of scientific achievements into production is the material basis of the existence and development of the science itself [4, p. 103].

N.V. Shyriayeva and O. B. Bilotserkivsky distinguish the following types of efficiency: budget; economic; social; technical; technological; investment; and ecological [5, p. 74-75]. The abovementioned categories, A.V. Cherep and Ye. M. Strilets complement with the legal, innovative and the efficiency of integration of insurance enterprises with banks [6]. In addition to economic efficiency, the researchers often highlight financial or commercial efficiency, which is designed to differentiate the interests of investors, owners and the state in the implementation of the innovative development program. Such a division is considered to be justified, since an innovative program that is successful from the point of view of some interested persons, can be considered unsuccessful by others.

Economic efficiency reflects the impact of the innovative project on the society as a whole. Indicators of profit(income) or savings are manifested at various levels of society: ranging from individuals to large enterprises and the state. Commercial (financial) efficiency takes into account the financial implications of project implementation for its direct participants - investors. The project's budget efficiency reflects the financial implications of project implementation for state and local budgets [7, p. 79].

Financial efficiency characterizes the efficiency of innovative activities aimed at improving the financial condition of the enterprise. The importance of distinguishing this category is determined by the fact that one of the most important tasks of the innovative program implementation is to ensure sustainable development of the enterprise on the basis of creating conditions for improving the financial and property status.

For evaluating the efficiency of an innovative program, the following methods commonly used in the investment project analysis are used:

- statistical: by return on investment (ROI), payback period (PP), an average rate of return (ARR), etc.;

- dynamic (discounted): by net present value (NPV), by profitability index (PI), by internal rate of return (IRR), by discounted payback period, DPP) etc.;

- real options methods: the Black-Scholes Option Pricing Model, the Cox-Ross-Rubinstein Binomial Options Pricing Model, and others.

The advantages and disadvantages of using these methods can be found in the works of Ukrainian and foreign researchers.

The scientists point out that they are not fully suited to assess the efficiency of innovation. This is due to the fact that the creation and use of innovations, as opposed to the investment project, usually involves a wide range of participants. The enterprise itself is mainly interested in the implementation of the investment project, as well as the investors financing it. In the innovative process, especially in the process of implementing a large innovative project, investors, research, development and project organizations, factories producing new products and consumers can be involved [8, p. 130]. Most of them are not suitable for the evaluation of financial efficiency since they do not provide tools for analyzing the system of financial and economic indicators of the enterprise activity.

The methodology for analyzing the financial effectiveness of the innovative development program of the enterprise, which is based on the assumption that a highly effective innovative program should ensure the improvement of the financial condition of the enterprise, is offered.

The implementation of the methodology is carried out in several successive stages:

1) selection of the indicators used to analyze the financial condition of the enterprise in six basic directions: analysis of the property status, profitability analysis, analysis of liquidity and 
solvency, analysis of financial stability, feasibility analysis, and business activity analysis. All indicators are divided into indicators-stimulants (growth indicates improvement in financial condition) and disinfectants (growth indicates a deterioration in the financial condition);

2) formation of the reporting data on the results of the innovative program implementation to determine the impact of an innovative activity on the financial condition of the enterprise;

3 ) conduction of analytical work, the result of which is the formation of an analytical map for determining the financial and economic efficiency of the innovative development program of the enterprise;

4) generalization of the results of the analysis, determination of the efficiency of the innovative development program and the formulation of proposals.

Stage 1. For the proposed methodology, 38 known indicators of the analysis of the financial condition, divided into 6 groups, are used:

1) indicators of the property status evaluation (the research of the use of non-current assets and their sources of formation): the coefficient of depreciation of fixed assets, coefficient of renewal of fixed assets, coefficient of fixed assets retirement, proportion of the active part of fixed assets;

2) indicators of profitability evaluation(the research of the activity efficiency by studying the ratio of profits/income and resources spent for their obtaining): the profitability of investment in ordinary shares, total profitability, the profitability of assets, rotation of non-current assets;

3) indicators of liquidity and solvency evaluation(the research of the adequacy of current assets for the settlement of current liabilities): the cash maneuverability, total coverage ratio, intermediate coefficient of coverage, absolute liquidity ratio, share of working capital in assets, share of inventories in current assets, share of own working capital in the coverage of stocks, coefficient of critical evaluation, rotation of stocks;

4) indicators of financial sustainability evaluation(the research of the possibilities of selffinancing and independence of the enterprise from external sources): the autonomy coefficient, debt and equity ratio, long-term ratio of capital employed, coefficient of maneuverability of own capital, coefficient of real value of fixed assets in assets, coefficient of financial dependence, coefficient of concentration of attracted capital, coefficient of structure of attracted capital;

5) indicators of profitability evaluation (the research of the level of return on costs, capital, resources): the profitability of sales, profitability of operational activity, return on equity capital, a period of return on equity, the profitability of fixed capital;

6) indicators of business activity evaluation (the research of turnover of assets and liabilities of the enterprise): the coefficient of total turnover of assets, turnover rate of mobile means, turnover rate of stocks, turnover rate of finished products, turnover rate of accounts receivable, average duration of turnover of accounts receivable, turnover rate of accounts payable, average duration of trade payables, capital productivity ratio of noncurrent assets, turnover rate of own capital.

In general, the selection of indicators depends on the detailed aim of the analysis. For example, if an analyst has doubts about the positive effect of innovative activity on the liquidity of the investigated enterprise, he may focus on the external analysis of solvency indicators for reporting periods.

The need for a comprehensive study of the abovementioned indicators is dictated by the fact that the positive impact of the results of the innovative program on one indicator may be cancelled out by a negative one - for others. For example, the improvement of property status by putting into operation of the latest non-current assets may be due to a deterioration of liquidity, since the funds, previously deduced from the business turnover of the enterprise, were spent on the development.

Stage 2. To determine the magnitude of the impact on the indicators of the financial condition analysis of the implementation results of the innovative development program of the enterprise, it should be taken into account that the change in the indicators in the period of program implementation occurs, including due to the impact of factors related to non-innovative activity (in particular, operational or financial). To solve this issue, we propose to develop an adjusted form of 


\section{A. Boychuk}

the Balance Sheet (Financial Condition Report) and the Income Statement (Statement of Total Income), which will be made on the basis of business operations of the enterprise directly related exclusively to the innovative activity. The implementation of this process in the accounting system will take place using the system of analytical subaccounts set up to the envisaged Schedule of Accounts. To simplify it, automated processing of accounting data can be used. As a result, forms of financial reporting will be received, formed on the results of the implementation of innovative projects that are a part of the innovative development program. The structure of the innovative Balance Sheet (Financial Condition Report) and the Income Statement (Statement of Total Income) do not differ from those adopted in the accounting practice and approved by the norms of the National Accounting Standard (Standard) 1 "General Requirements to the Financial Statements", but in content they will contain data on assets, liabilities, capital, income, expenses, financial results and total income from innovative activities for the reporting period. It is appropriate to choose a quarter for such a period for the possibility of reconciliation and adjustment with indicators in the articles of usual financial statements. The starting date for the compilation of reports will be the date of the start of the innovative program implementation, and the final date is the completion of the innovative program.

In the balance sheet, by the results of innovative activities the assets, accumulated as a result of such activities, liabilities associated with it, as well as the portion of the capital of the enterprise used for its financing, are reflected.

The Adjusted Income Statement(Statement of Total Income) contains information on the income and expenses associated with the innovative activity of the enterprise.

Both reporting forms are used exclusively for the internal needs of the enterprise and are useful in the case of analysis of the impact of the results of the innovative program implementation on the financial condition of the research object.

Stage 3. To determine the impact of indicators on the financial condition of the enterprise, a number of actions related to the calculation of the following should be carried out: a basic financial indicator based on the results of economic activity (is used as a result in the analysis of the impact of other indicators); the discounted financial indicators on the results of innovation and other (except innovative) activity (is used to determine the range of changes in indicators of innovative activity); the basic financial indicator on the results of innovative activity (is used as a factor of influence on the result indicator) (Fig. 2).

Formation of the optimal Formation of the critical boundary of the range boundary of the 1st range

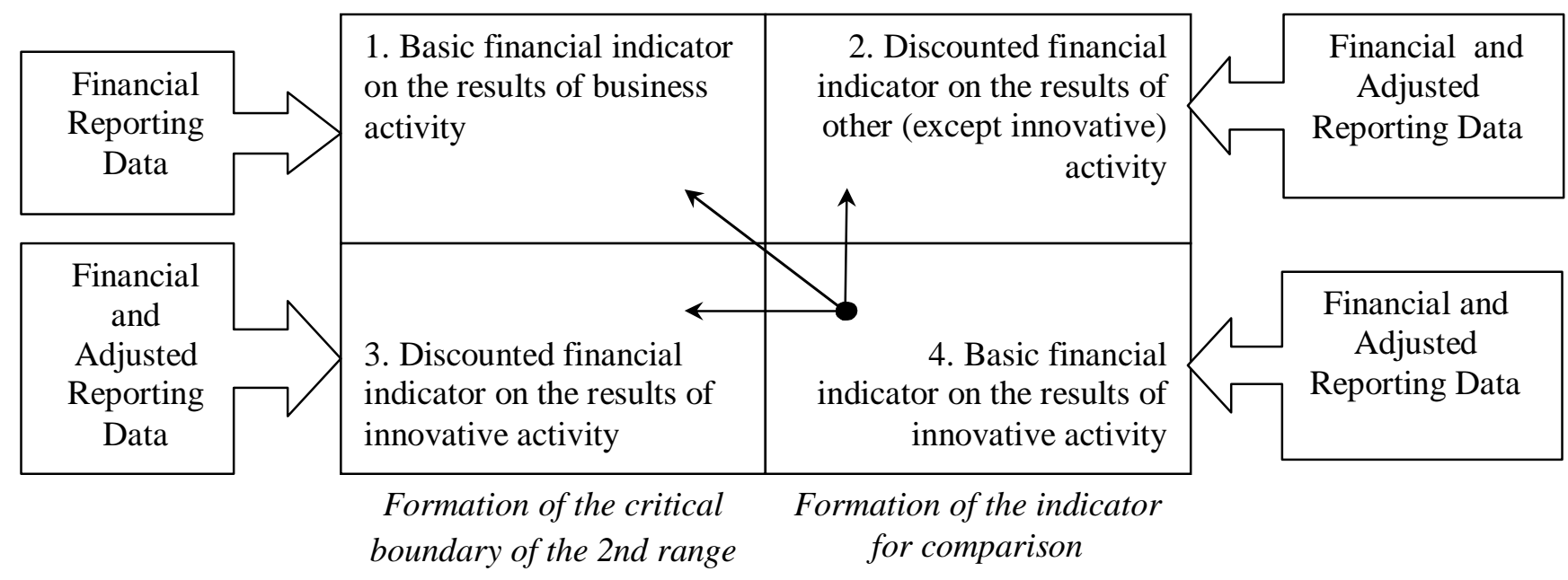

Fig.2 Principal scheme of the formation of comparable values of indicators, calculated on the basis of financial and adjusted reporting

Source: author's idea 
The basic financial indicator is calculated on the basis of Balance Sheet (Financial Condition Report) and the Income Statement (Statement of Total Income), as well as additional analytical data, and is used to form the boundary value that can be considered as the basis for comparing the same indicator, calculated on the basis of the reporting made up of the effects of innovation.

The sum of the discounted financial indicator on the results of other (except innovative) activity and the discounted financial indicator on the results of innovative activity is equal to the basic financial indicator on the results of economic activity.

The numerical value of the basic financial indicator on the results of innovative activity can be found in one of the four ranges:

- range 1: the higher value of the basic financial indicator on the results of economic activity;

- range 2: the higher value of one of the discounted financial indicators, but the lower value of the basic financial indicator on the results of economic activity;

- range 3: between the values of the discounted financial indicators;

- range 4: the lower value of one of the discounted financial indicators on the results of economic activity. It may be both a discounted financial indicator, calculated on the basis of the impact of the innovative activity on the results and similar, calculated on the basis of the impact of another (operational, financial) activity on the results.

Stage 4. The mutual impact of the results of innovative and other activities on the financial condition of the enterprise can be as follows:

1) complementary positive - the positive impact of the results in both types of activities;

2) reverse with the positive impact of innovative activity;

3) reverse with the positive impact of the results of other activities;

4) complementary negative - the negative impact of the results in both types of activity.

For maximizing the efficiency of management options following the results of the analysis of the financial and economic efficiency of the innovative development program, the evaluation of projects is carried out after each stage of implementation.

\section{Conclusions and perspectives for further research}

Thus, the proposed method of evaluating the financial component of the efficiency of the innovative development program of an enterprise enables to determine the impact of the results of the innovative program on the financial condition of the enterprise by eliminating the impact of other factors related to operational and financial activities. Prospects for further research are to develop a methodology for monitoring the implementation process of the innovative development program of an enterprise.

\section{References}

1. Tymoshchuk M.R. (2014). Indicative planning as the basis of balanced socio-economic development. [Scientific Bulletin of UNFU], 24.5, 302-308. [in Ukrainian].

2. Voronov M.P., Hryhorovych, V.R. \& Voronov, E.M. (2012). Administrative and legal aspects of indicative planning of public administration and regulation in Ukraine. Chasopys Akademii advokatury Ukrainy [Journal of the Academy of Advocacy of Ukraine], 14, 01-06. [in Ukrainian].

3. Bidniak M.N. (2013). Methodology of indicative method of management. Ekonomika $i$ menedzhment kultury [Economy and management of culture], $1, \quad 28-32$. [in Ukrainian].

4. Shinkareva E.S. (2008). Methodical approaches to the assessment of innovative activities of enterprises. Ekonomicheskie nauki [Economic sciences], 3 (19-1), 103-105. DOI: 10.17238/issn2071-2243.2016.4.281. [in Russian].

5. Shyrjajeva N.V., \& Bilocerkivsjkyj O.B. (2015). Analysis of methods of heating systems social and economic efficiency estimation. [The bulletion of transport and industry economics], 51, 73-77. [in Ukrainian].

6. Cherep A.V. (2013). Efficiency as an economic category. Efektyvna ekonomika [Effective 


\section{A. Boychuk}

economy], $1 . \quad$ Retrieved from http://www.economy.nayka.com.ua/?op=1\&z=17 27 [in Ukrainian].

7. Fedosova R.N. \& Pimenov S.V. (2009). Modern tools for assessing the effectiveness of innovation projects. Vestnik OGU [Herald of OSU], 5, 7881. [in Russian].

8. Titova O.V. (2015). Complex estimation of efficiency innovation project. Vestnik SGUGiT [Herald of SSUGT], 3(31), 129-136. [in Russian]. 